\title{
Describing the chemical singularity of the Spanish protected designations of origin for virgin olive oils in relation to oils from neighbouring areas
}

\author{
By D.L. García-González ${ }^{1}$, N. Tena ${ }^{1}$ and R. Aparicio ${ }^{*}$ \\ ${ }^{1}$ Instituto de la Grasa (CSIC), Avda. Padre García Tejero 4, E-41012 Sevilla, Spain \\ *Corresponding author: aparicio @ cica.es
}

\begin{abstract}
RESUMEN
Descripción de la singularidad química de denominaciones de origen protegidas españolas en relación a sus áreas olivareras vecinas.

Las denominaciones de origen protegidas (DOPs) han demostrado ser un marco de regulación de éxito para la protección de aceites de oliva vírgenes singulares que tienen propiedades particulares. Sin embargo, en ocasiones, el registro de DOPs nuevas y la demarcación de las áreas geográficas asociadas a ellas se basan en aspectos administrativos más que en datos químicos objetivos. En este trabajo se emplea la composición química de ácidos grasos, hidrocarburos, alcoholes, esteroles y metilesteroles para demostrar las diferencias entre aceites de oliva vírgenes de denominaciones de origen protegidas y los aceites producidos en las áreas circundantes. Se han estudiado tres casos (DOP Estepa, DOP Montoro-Adamuz y Campiña de Jaén) que realmente representan tres situaciones que combinan variaciones de cultivar y de características pedoclimáticas. Se seleccionaron, con el test de Brown-Forsythe, una modificación de ANOVA, los compuestos químicos que mostraban buenas características para la clasificación de muestras, y esta capacidad se comprobó posteriormente mediante análisis de componentes principales. Los aceites de las DOPs Estepa y Montoro-Adamuz mostraron diferencias claras en su composición química, mientras que los aceites producidos en Campiña de Jaén formaron un grupo de muestras que se solapó en gran medida con los aceites de las áreas geográficas próximas, probablemente debido al casi exclusivo monocultivar (Picual) en toda la provincia de Jaén.
\end{abstract}

PALABRAS-CLAVE: Aceite de oliva virgen - Compuestos minoritarios - Denominación de origen protegida - Trazabilidad geográfica.

\section{SUMMARY}

Describing the chemical singularity of the Spanish protected designations of origin for virgin olive oils in relation to oils from neighbouring areas.

The protected designations of origin (PDOs) have proven to be a successful regulatory framework to protect singular virgin olive oils that have distinctive properties. However, sometimes the registration of new PDOs and the demarcation of the geographical areas associated to them are based on administrative issues rather than objective chemical data. In this work, the chemical compositions of fatty acids, hydrocarbons, alcohols, sterols and methyl sterols have been used to prove the differences between a PDO virgin olive oil and the oils produced in the surrounding areas. Three cases were studied (PDO Estepa, PDO Montoro-Adamuz, and
Campiña de Jaén) which actually mean three different situations that combine variations in cultivar and pedoclimatic characteristics. The chemical compounds that showed a better ability to classify samples were selected by the BrownForsythe test, a particular modification of ANOVA, and this ability was later visualized in a principal component analysis. The oils from PDOs Estepa and Montoro-Adamuz showed clear differences in their chemical compositions, while the oils from Campiña de Jaén formed a group of samples which greatly overlapped with the oils from surrounding areas, probably due to the lack of variation in cultivar (Picual) throughout the province of Jaén.

KEY-WORDS: Geographical traceability - Minor compounds - Protected designation of origin - Virgin olive oil.

\section{INTRODUCTION}

Consumer interest in a reliable geographical declaration of foods has increased over the last years. This consumer demand for geographical identification has led to a regulation of the European Community (EC, 2006) which establishes a controlled labelling of food products, virgin olive oil among others, based on geographical indications such as Protected Designation of Origin (PDO). In the particular case of virgin olive oil this information is deemed as an additional guarantee of quality, authenticity, tradition and safety (García-González and Aparicio, 2010). This legal framework intends to fulfill consumer expectation and to provide better protection for virgin olive oils from diverse areas of olive growing with particular sensory and chemical characteristics. Consequently, the registration of PDOs is related to geographical traceability, since they are associated with a particular area. Furthermore, PDOs are associated with authentication in order to fight against falsification or mislabelling since olive oils within the regime of a PDO usually have a higher market price and therefore are vulnerable to fraud (Cosio et al., 2006).

The geographical identification has a special interest for extra virgin olive oil, the quality of which is highly related to the cultivars employed and to the environmental conditions of growth (Pafundo et al., 2005). The unique characteristics of virgin olive 
oils of a PDO should be explained from their chemical compositions. Supporting the distinctive properties of PDOs with chemical data would allow consumers to distinguish them from other PDOs and would also protect them from false copies, the latter representing the greatest potential risk. Thus, if the characteristics of PDOs are based on common sensory descriptors (e.g. fresh grass, almond) or chemical contents (e.g. percentages of fatty acids or content of phenols between 400 and 600 ppm), soil characteristics (e.g. regosol) or the historical references, the supposed peculiarities of PDOs might not be enough to reveal differences from other PDOs or non PDO oils and, in consequence, they might not be protected from hypothetical but foreseeable false copies.

The peculiarities of olive oils should be based on physicochemical variables that do not change over time; for example, compounds like phenols and pigments should not be used because their concentrations vary with ripeness and shelf life, and hence they do not mean any guarantee determining the genuineness of a virgin olive oil. Fatty acids, sterols and hydrocarbons, among other series of chemical compounds, do mean, on the contrary, the inherent characteristics of VOOs produced in a PDO if their profiles are statistically different from other VOOs.

This work is focused on the VOOs from Spanish PDOs recently submitted to the Commission of the European Community: Estepa, Montoro-Adamuz and Campiña de Jaén. These three cases have been selected to explain current problems in the chemical characterization of potential PDOs. The first case involves the study of a small PDO surrounded by orchards with the same main cultivar and similar climate and soil. The second case corresponds to a PDO with several cultivars - two of them being major cultivars - whose virgin olive oils (VOOs) are distinguished from its neighbours due the percentages of mixtures of $\mathrm{VOO}$ from the major and diverse minor cultivars. The third example corresponds to a geographical zone that covers most of the Spanish province of Jaén whose production means more than $15 \%$ of the worldwide VOO production and is surrounded by PDOs with the same cultivar. Furthermore, the climate, soil and altitude of the orchards of the province of Jaén are not homogenous but diverse. This study describes the differences in the concentrations of 64 chemical compounds in the VOOs produced by the co-operative societies of each one of these three potential PDOs and their neighbouring producing zones.

\section{MATERIALS AND METHODS}

\subsection{Samples}

VOO samples were purchased at the cooperative societies and particular olive mills during two different harvests (Table 1). This procedure protects the study against mixtures of
Table 1

Codes of the samples analyzed in this study

\begin{tabular}{|c|c|c|c|}
\hline Code & $\begin{array}{c}\text { Sample } \\
\text { description }\end{array}$ & Province & $\begin{array}{c}\text { No. of } \\
\text { Samples }\end{array}$ \\
\hline P1 & PDO “Estepa” & Sevilla & 24 \\
\hline E1 & Northern Málaga & Málaga & 20 \\
\hline E2 & “Campiña alta” area & Córdoba & 20 \\
\hline P2 & $\begin{array}{l}\text { PDO "Montoro- } \\
\text { Adamuz" }\end{array}$ & Córdoba & 16 \\
\hline M1 & $\begin{array}{l}\text { "Los Pedroches" } \\
\text { area }\end{array}$ & Córdoba & 13 \\
\hline M2 & PDO "Baena" & Córdoba & 29 \\
\hline M3 & $\begin{array}{l}\text { PDO "Priego de } \\
\text { Córdoba" }\end{array}$ & Córdoba & 14 \\
\hline P3 & Campiña de Jaén & Jaén & 102 \\
\hline J1 & $\begin{array}{l}\text { PDO "Sierra } \\
\text { Mágina" }\end{array}$ & Jaén & 24 \\
\hline J2 & $\begin{array}{l}\text { PDO "Sierra del } \\
\text { Segura" }\end{array}$ & Jaén & 22 \\
\hline J3 & "Sierra Sur" area & Jaén & 17 \\
\hline
\end{tabular}

oils from different geographical origins. All the samples were analyzed in duplicate.

Thus, 24 VOO samples were from the olive mills of PDO "Estepa" (henceforth P1), a region located in the province of Seville (Andalusia, Spain), while 40 VOO samples (code E1 and E2) were from its neighbouring olive mills in the provinces of Málaga and Córdoba (Figure 1). Hojiblanca is the major variety though var. Arbequina is gaining importance over the years due to intensive plantations in P1 (22\% in 2009) (personal communication), while var. Picual means more than $20 \%$ of the plantations in E2 (Barranco et al., 2005).

In the province of Córdoba (Andalusia, Spain) the PDO "Montoro-Adamuz" (henceforth P2) is formed by eight geographical locations where olive mills were sampled for two years before obtaining a total of 16 VOO samples. The major cultivars are Nevadillo Negro and Picual (also known as Nevadillo Blanco). Virgin olive oils from neighbouring cooperatives located in the geographical zone "Los Pedroches" and PDOs "Baena" and "Priego de Córdoba" (coded M1, M2 and M3, respectively), 56 samples in total, were also chemically characterized for this study (Figure 1).

The geographical area of the potential PDO "Campiña de Jaén" (Jaén, Andalusia, Spain) (henceforth, P3) comprises 51 geographical locations (villages) whose olive mills were sampled. The contrast is constituted by 63 samples from three neighbouring PDOs (coded $\mathrm{J} 1, \mathrm{~J} 2$ and J3) (Figure 1). VOOs are from var. Picual, which makes up more than $95 \%$ of the entire production. 


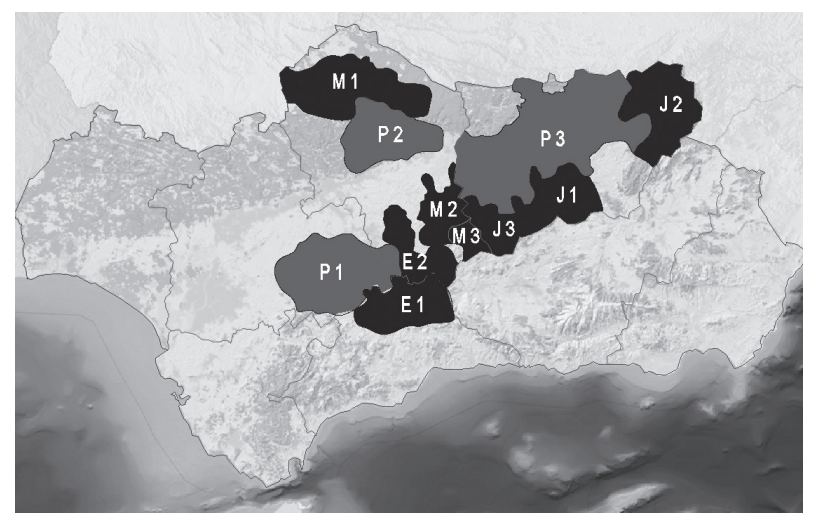

Figure 1

Map of Andalusia (Spain) with the olive growing areas considered in the study. Note: P1 (PDO "Estepa"), P2 (PDO "Montoro-Adamuz"), P3 (“Campiña de Jaén”). The surrounding areas are labelled with $\mathrm{E}, \mathrm{M}$, and $\mathrm{J}$ letters.

\subsection{Analytical Methods}

Table 2 shows the chemical compounds identified and quantified for this study which have been clustered into fatty acids, hydrocarbons (n-alkanes and n-alkenes), alcohols (linear, terpenic and diterpenic) and sterols and methyl-sterols.

Fatty acid (FA) determination was performed according to the official method of the EC no.2568/91 (EC, 1991). Chromatographic analyses were carried out on a Varian 3900 chromatograph
(Varian, Walnut Creek, CA) equipped with a flame ionization detector (FID).

The determination of alkanes and alkenes was performed by preparing $1 \mathrm{~mL}$ of a standard solution of $n$-eicosane to which $20 \mathrm{~g}$ of oil was added. The mixture was saponified for 30 min with $75 \mathrm{~mL}$ of $10 \%$ ethanolic potassium hydroxide. Distilled water $(100 \mathrm{~mL})$ was added and the solution was extracted twice with hexane $(100 \mathrm{~mL})$. The extracts were washed with three $100 \mathrm{~mL}$ volumes of a mixture of ethanol-water (1:1) and the water was removed with anhydride sodium sulphate. The solution was evaporated to dryness in a rotary evaporator at $30{ }^{\circ} \mathrm{C}$ under reduced pressure to reduced volume $(1 \mathrm{~mL})$. The hydrocarbons were separated from other components by column chromatography $(50 \mathrm{~cm} \times$ $1.5 \mathrm{~cm}$ i.d., with a Teflon stopcock, and filled with 15 $\mathrm{g}$ of silica gel slurried with hexane). The total unsaponifiable matter (0.2 g approx.) was dissolved in $1 \mathrm{~mL}$ of hexane and the solution was poured into the column head. The flask was rinsed three times with hexane, approximately $1 \mathrm{~mL}$ each time. These rinses were added to the column head, waiting for the previous addition to pass completely into the column. The sample was then eluted with hexane at a rate of about $1 \mathrm{~mL} / \mathrm{min}$. An aliquot of $60 \mathrm{~mL}$ was collected and then concentrated to approximately $1 \mathrm{~mL}$ in the rotary evaporator at $30^{\circ} \mathrm{C}$ under reduced pressure and the resulting sample was analyzed by gas chromatography. A fused silica column HP-5

Table 2

Chemical compounds quantified in the samples

\begin{tabular}{llll}
\hline Fatty Acids & n-Alkanes & Terpenic Hydrocarbons & Linear Alcohols \\
\hline Palmitic & C14 & $\alpha$-Copaene & Docosanol \\
Palmitoleic & C16 & Eremophylene & Tetracosanol \\
Margaric & C17 & Muurolene & Pentacosanol \\
Margaroleic & C18 & $\alpha$-Farnesene & Hexacosanol \\
Stearic & C19 & Allofarnesene & Octacosanol \\
Oleic & C21 & & \\
Linoleic & C22 & Terpenic Alcohols & Methyl-sterols \\
Linolenic & C23 & Taraxerol & Gramisterol \\
Arachidic & C24 & Dammaradienol & Cycloeucalenol \\
Gadoleic & C25 & $\beta$-Amirine & 24-Ethyllophenol \\
Behenic & C26 & Butirospermol & Citrostadienol \\
& C27 & Cycloarthenol & Obtusifoliol \\
n-Alkenes & C29 & 24-Methylene-cycloarthanol & \\
C17:1 & C30 & Cyclobranol & Sterols \\
C23:1 & C31 & 24-Methylene-lanosterol & Campesterol \\
C24:1 & C32 & & Stigmasterol \\
C25:1 & C33 & Diterpenic Alcohols & $\beta$-Sitosterol \\
& C34 & Phytol & $\Delta^{5}$-Avenasterol \\
& C35 & Erythrodiol & $\Delta^{7}$-Stigmasterol \\
\hline
\end{tabular}


$(30 \mathrm{~m} \times 0.32 \mathrm{~mm}$ i.d $\times 0.25 \mu \mathrm{m}$ film thickness $)$ (Agilent Technologies, Madrid, Spain) was used. Hydrogen was employed as carrier gas with an incolumn pressure of 10 psi. The temperatures of the injector and detector (FID) were set at $290{ }^{\circ} \mathrm{C}$ and $320{ }^{\circ} \mathrm{C}$, respectively. The oven temperature was held at $110^{\circ} \mathrm{C}$ for $6 \mathrm{~min}$ and programmed to rise to 4 ${ }^{\circ} \mathrm{C} / \mathrm{min}$ to a temperature of $300^{\circ} \mathrm{C}$, where it was held for 8 minutes. An injection volume of $1 \mu \mathrm{L}$ was used (Aparicio and Alonso, 1994).

The method for the saponification, the isolation of the non saponifiable fraction and the separation of the sterols of this fraction in olive oil samples was carried out according to the method described by the Official Journal of the European Community (EC, 1991). The bands of sterols and alcohols were, however, independently isolated and extracted with diethyl ether $(30 \mathrm{~mL})$ and evaporated to dryness again in the rotary evaporator. Next, the flasks were dried with $\mathrm{N}_{2}$ for 10 minutes and silanized with $200 \mu \mathrm{L}$ of a mixture of hexamethyldisilazane, pyridine and trimethylchlorosilane (9:3:1) and then $1 \mu \mathrm{L}$ of each solution was injected into the gas chromatograph. A fused silica column HP-5 (30m $\times 0.32 \mathrm{~mm}$ i.d $\times 0.25 \mu \mathrm{m}$ film thickness) was also used for the analyses of sterols and alcohols. Hydrogen was employed as carrier gas with an in-column pressure of 10 psi. The temperatures of the injector and detector (FID) were set at $290^{\circ} \mathrm{C}$ and $320^{\circ} \mathrm{C}$ respectively. For alcohol separation the oven temperature was held at $200{ }^{\circ} \mathrm{C}$ for $8 \mathrm{~min}$ and programmed to rise $5^{\circ} \mathrm{C} / \mathrm{min}$ up to a temperature of $210^{\circ} \mathrm{C}$, where it was held for $15 \mathrm{~min}$. The oven temperature was held at $263^{\circ} \mathrm{C}$ for the separation of sterols.

\subsection{Statistical Analysis}

The data matrix (chemical compounds $\times$ samples) was analyzed by uni- and multi-variate mathematical procedures. The Brown-Forsythe test was used to determine the homogeneity of the variances and selection of variables (chemical compounds) with univariate discriminate ability. The Brown-Forsythe test is a modification of the ANOVA and t-tests for mean differences in which the homogeneity of variance assumption is not as crucial. This procedure gives quite accurate error rates even when the underlying distributions for the raw scores deviate significantly from the normal distribution (Olejnik and Algina, 1987). Principal Component Analysis (PCA) was used to determine whether the set of selected variables was able to discriminate the production of PDOs from their neighbouring olive oil producers. The statistical analyses were carried out with Statistica 6.0 (Statsoft Inc., Tulsa, OK)

\section{RESULTS AND DISCUSSION}

The recent economic and regulatory importance of VOO protected designation of origins (PDO) and protected geographical indication (PGI) has challenged the researchers to implement methodologies that control the mislabelling of VOO geographical origin (e.g. false PDOs), which is one of the priorities of the producers and the anti-fraud administrations. There is no single compound in the oil that can be directly related to geographical origin but the concentrations of some of them are partially modulated by the characteristics of the growing area and, obviously, the cultivars.

The selection of the chemical series, described in Table 2, has not been random since they are related to different factors affecting olive oil chemical composition. Those factors conform to the chemical profile of the oils produced in particular geographical origins. Thus, for example, olive oils from orchards located above $1000 \mathrm{~m}$ have a profile of sterols and terpenic alcohols different from orchards located in valleys (Ferreiro and Aparicio, 1992) while olive oils from orchards located in different hemispheres usually show different profiles of polyunsaturated fatty acids (Alonso and Aparicio, 1993; Ollivier et al., 2006; D'Imperio et al., 2007). The characterization of oils from different geographical origins is, however, mainly due to cultivars (Guinda et al., 1996; Aparicio 2000; Aparicio and Luna, 2002; De Caraffa et al., 2008) but also to climate (Aparicio et al., 1994b), soil and agricultural practices (Morales et al., 1999).

The conclusion of previous studies is that because the olive tree is a live organism, the inherent chemical characteristics of a particular cultivar are modulated by the climate (dry vs. humid), the availability of elements and nutrients (i.e. soil), the agricultural practices (e.g. irrigation, fertilization), the olive maturation at harvesting time (Frías et al., 1991) and the extraction and storage technologies as the main external variables. Changes in these variables cause the variability in the concentrations of the chemical compounds. The variability in the profile of the chemical compounds observed over the years is then decisive to determine if a geographical area (e.g. PDO, PGI) produces particular VOOs regardless of the above cited variables.

Three Spanish geographical zones located in Andalusia - P1 (Estepa), P2 (Montoro-Adamuz) and P3 (Campiñas de Jaén) - have claimed that they produce particular VOOs as they are different even from their neighbouring orchards.

\subsection{Studying a PDO surrounded by olive orchards with the same main cultivar and soils}

Applying the Brown-Forsythe algorithm, nine chemical compounds in Table 2 showed partial ability (Table 3) to distinguish VOOs produced in PDO Estepa (P1) from its neighbouring orchards: "Hojiblanca" (E1) and "Aceites de Córdoba" (E2). As the major cultivar (Hojiblanca) is common to all these geographical zones, the differences among P1 and its neighbours E1 and E2 are not in the concentrations of major but in the minor compounds, probably due to 
Table 3

Values (mean \pm standard deviation) of the chemical compounds characterizing VOOs produced in Estepa (P1) and its neighbouring orchards (E1, E2)

\begin{tabular}{|c|c|c|c|c|c|}
\hline \multirow{2}{*}{ Chemical compound } & \multicolumn{3}{|c|}{ Mean \pm Standard deviation } & \multicolumn{2}{|c|}{$\mathbf{p}$} \\
\hline & P1 & E1 & E2 & P1 vs. E1 & P1 vs. E2 \\
\hline Palmitic acid ${ }^{\mathrm{a}}$ & $10.14 \pm 0.78$ & $8.30 \pm 1.12$ & $9.50 \pm 0.84$ & 0.000 & 0.043 \\
\hline Palmitoleic acid $^{\mathrm{a}}$ & $0.85 \pm 0.20$ & $0.52 \pm 0.13$ & $0.78 \pm 0.14$ & 0.000 & 0.286 \\
\hline Docosanol $^{b}$ & $1.50 \pm 0.44$ & $2.37 \pm 0.93$ & $2.62 \pm 1.20$ & 0.005 & 0.003 \\
\hline Tetracosanol $^{\mathrm{b}}$ & $2.77 \pm 0.88$ & $5.17 \pm 2.31$ & $5.22 \pm 2.03$ & 0.002 & 0.000 \\
\hline$\Delta^{5}$-Avenasterol ${ }^{\mathrm{b}}$ & $12.01 \pm 2.18$ & $13.58 \pm 4.62$ & $9.93 \pm 2.15$ & 0.277 & 0.014 \\
\hline 24-Methylene-cycloarthanol ${ }^{b}$ & $70.82 \pm 18.90$ & $100.96 \pm 35.69$ & $101.09 \pm 29.34$ & 0.012 & 0.003 \\
\hline Cycloarthenol $^{b}$ & $15.34 \pm 4.12$ & $20.01 \pm 5.03$ & $15.11 \pm 5.32$ & 0.015 & 0.898 \\
\hline C21 (Heneicosane) ${ }^{b}$ & $0.03 \pm 0.01$ & $0.03 \pm 0.01$ & $0.03 \pm 0.01$ & 0.047 & 0.888 \\
\hline C35 (Pentatriacontane) ${ }^{\mathrm{b}}$ & $0.02 \pm 0.01$ & $0.03 \pm 0.01$ & $0.04 \pm 0.03$ & 0.009 & 0.003 \\
\hline
\end{tabular}

Note: P1, "Estepa"; E1, oils from neighbouring orchards in Málaga; E2, oils from neighbouring orchards in Córdoba; ', \%; b $\mathrm{mg} / 100 \mathrm{~g}$

variations in maturity, climate or agricultural practices. On the other hand, the differences in the minor composition of the oils may be modified by the presence of low percentages of minor varieties (Arbequina, Manzanilla and Lechín).

Palmitic and palmitoleic acids were the only two fatty acids selected to distinguish oils from PDO "Estepa" from those of the surrounding areas. Fatty acids have been previously applied for the geographical identification of oils by country and the two selected acids have also shown ability to distinguish the oils produced in Andalusia from the oils of other Spanish regions (García-González et al., 2009). The difference in maturity of the olives could explain the variations in the concentration values, rather than assuming climate or altitude effects. Thus, palmitic acid is the end-product in the biosynthesis of fatty acids and the concentration of this fatty acid evolves during maturity, reducing the concentration in the last ripeness stages (Ajana, et al., 1998; Ninni, 1999). The olives are usually harvested at earlier stages in the production of PDO Estepa in comparison with non PDO oils to guarantee the sensory properties and desired stability (higher content of phenols). On the other hand, the ability of palmitic and palmitoleic acids to classify the geographical origin of olive oils has been attributed to the low variability between crop seasons (Alessandri et al., 1999).

The lower concentration of 24-methylenecycloarthanol in $\mathrm{P} 1$ compared to the areas E1 and E2 is even more remarkable, the latter two showing similar values $(\sim 100 \mathrm{mg} / 100 \mathrm{~g})$. Although it is thought that 24-methylene-cycloarthanol is synthesized by a methylation reaction of cycloarthenol (Benveniste, 2002; Sakouhi et al., 2010), the latter does not show as many differentiation properties as the former. 24-Methylene-cycloarthanol is an end product in sterol biosynthesis and the concentration of this compound is highly dependent on maturity. Thus a specific accumulation is observed in the last ripeness stages (Stitiet et al., 2007). Since the concentration of this compound increases during ripeness (Frega and Lercker, 1986), the concentration values in $\mathrm{P} 1$ point out that their olives are milled when they are less ripe than those from E1 and E2. This difference in concentration also agrees with the percentage of VOOs from var. Arbequina in P1, around $22 \%$ (personal communication), since this cultivar is harvested less ripe than var. Hojiblanca and Picual. The presence of Arbequina cultivar in the blends of this PDO explains that VOOs from P1 are greener and slightly more bitter than monovarietal oils from Hojiblanca and Picual cultivars. In fact, the concentration of 24-methylenecycloarthanol has been used in classifying models to distinguish oils from Arbequina varieties from other varieties due to the low concentration found in this cultivar (Calvente and Aparicio, 1995).

The concentration of $\Delta^{5}$-avenasterol has been associated with the percentage of stone with respect to the pulp in milled olives. The oils from E2 show lower values for this compound and this result agrees with the percentage of VOOs from var. Picual in this area. The lower concentration of aliphatic alcohols is characteristic of P1 (Aparicio et al., 1994a) and it has been related to a particular management of the olive oil extraction process (hammer milling and malaxing conditions) in P1. The differences in the percentages of fatty acids are also due to the varietal effect, since the percentage of VOOs from var. Hojiblanca is much higher (>90\%) in E1 (Aparicio, 2000). Finally, hydrocarbons are related not only to cultivars (Guinda et al., 1996) but also to the kinds of soil (García-González et al., 2009).

None of the compounds selected by the BrownForsythe test were, however, able to discriminate oils from the three geographical origins (P1, E1 and E2) simultaneously. The non-supervised statistical procedure of Principal Component Analysis (PCA) was then applied with the nine selected compounds (Table 3 ) in order to check the ability of these compounds to discriminate VOOs from the three geographical zones simultaneously by means of two factors. 


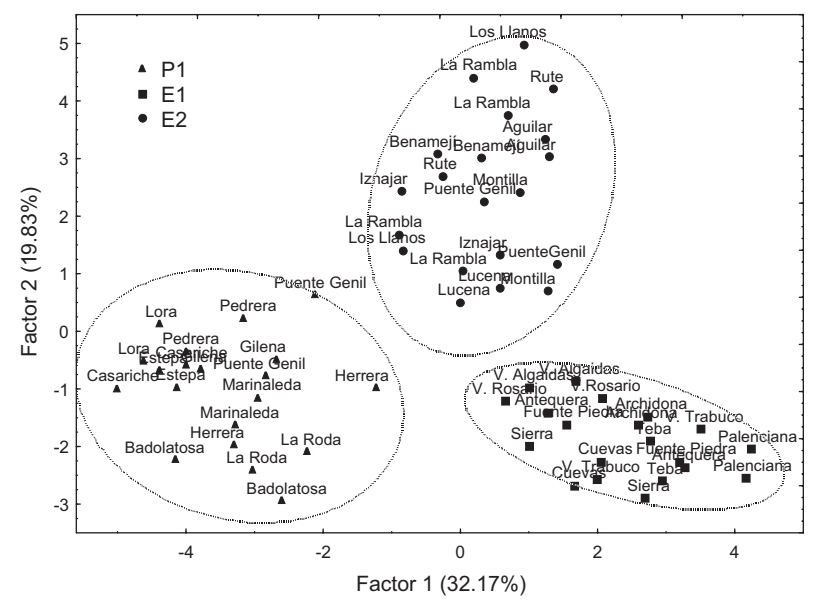

Figure 2

Principal Component Analysis of VOOs produced in PDO "Estepa" and in some neighbouring orchards in Málaga (E1) and Cordoba (E2). Note: The names are of the villages where the olive mills are located.

Figure 2 shows that there are three great groups surrounded by their ellipses of confidence at $85 \%$. The groups correspond to the geographical zones $\mathrm{P} 1, \mathrm{E} 1$ and E2, and the names inside the ellipses are the villages where the olive mills are placed. The ellipses show that it is possible to distinguish VOOs produced inside P1 from those produced in cooperative societies located in its surroundings without their oil chemical profiles overlapping. The lower homogeneity in the VOOs from P1 is partially due the olive mills that are located far enough from the PDO core (e.g. mills in Puente Genil, Córdoba).

\subsection{Studying a PDO surrounded by olive orchards with different soils and cultivars}

This study analyzes the case of a PDO completely surrounded by other olive growing areas whose VOOs result from a mixture of var. Picual (main cultivar) and several other cultivars in percentages that vary from one olive growing zone to another. None of the seven compounds selected by the Brown-Forsythe test (Table 4) is able to discriminate oils from the four

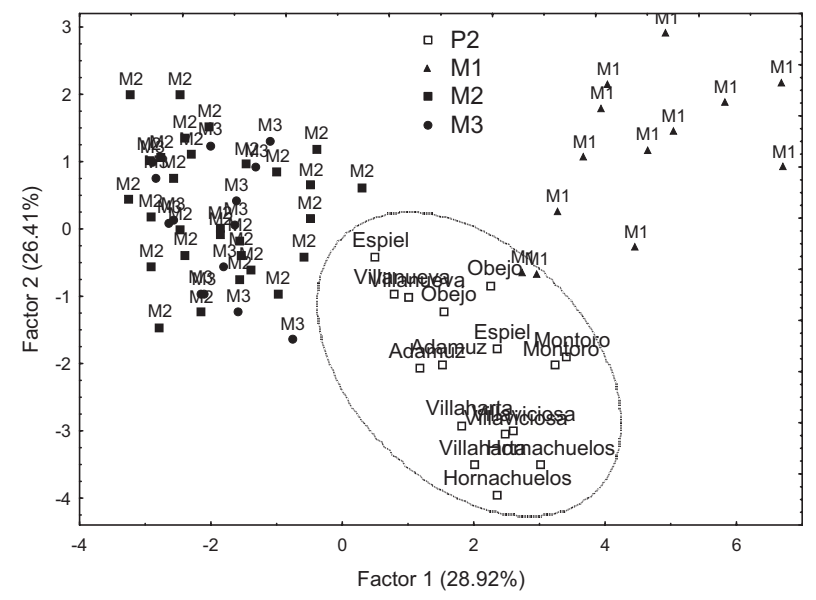

Figure 3

Principal component analysis of VOOs produced inside PDOs "Montoro-Adamuz" (the names of the villages where olive mills are located are given), "Baena" (M2), "Priego de Córdoba" (M3) and the geographical zone of "Pedroches" (M1).

geographical origins (P2, M1-M3) simultaneously. However, two of them (24-methylene-cycloarthanol and cycloeucalenol) are able to distinguish the VOOs of P2 from the other geographical zones with $p<0.95$. Table 4 also shows that the VOO chemical compounds of two neighbouring PDOs, Baena (M2) and Priego (M3), are very similar. Four of the chemical compounds show lower concentrations in P2.

The concentration of $\Delta^{5}$-avenasterol in VOOs from P2 seems to be related to the percentage of var. Picual in the resulting VOOs while the lower concentration of 24-methylene-cycloarthanol along with cycloarthenol, which is derived from squalene, have already been explained by the early harvesting of the olives (Stiti et al., 2007).

The non-supervized, statistical procedure of Principal Component Analysis (PCA) was also run with the selected compounds (Table 4) in order to know if these compounds were able to discriminate VOOs from those three geographical zones simultaneously by means of two factors. Figure 3 shows the three great groups of samples. The names inside of the confidence ellipse at $85 \%$

Table 4

Values (mean \pm standard deviation) of the chemical compounds characterizing VOOs produced in Montoro-Adamuz (P2) and its neighbouring orchards

\begin{tabular}{|c|c|c|c|c|c|c|c|}
\hline Chemical Compound $^{\mathrm{a}}$ & $\mathbf{P 2}^{\mathrm{b}}$ & $M 1^{b}$ & M2 $^{\mathrm{b}}$ & M3 $^{b}$ & $\mathrm{P} 2$ vs. $\mathrm{M} 1^{\mathrm{c}}$ & $\mathrm{P} 2$ vs. $^{\mathrm{M} 2}{ }^{\mathrm{c}}$ & $\mathrm{P} 2$ vs.M3 ${ }^{\mathrm{c}}$ \\
\hline Cycloeucalenol & $3.39 \pm 0.50$ & $5.09 \pm 0.49$ & $5.28 \pm 0.43$ & $5.64 \pm 0.44$ & 0.022 & 0.014 & 0.002 \\
\hline Erythrodiol & $2.75 \pm 0.17$ & $3.94 \pm 0.27$ & $2.33 \pm 0.17$ & $2.55 \pm 0.29$ & 0.002 & 0.154 & 0.578 \\
\hline Docosanol & $2.47 \pm 0.23$ & $5.18 \pm 0.51$ & $2.36 \pm 0.16$ & $2.54 \pm 0.26$ & 0.000 & 0.702 & 0.840 \\
\hline$\Delta 5$-Avenasterol & $7.11 \pm 0.67$ & $8.22 \pm 0.41$ & $10.07 \pm 0.34$ & $9.44 \pm 0.63$ & 0.160 & 0.000 & 0.018 \\
\hline Taraxerol & $0.93 \pm 0.05$ & $0.96 \pm 0.07$ & $0.67 \pm 0.04$ & $0.60 \pm 0.04$ & 0.709 & 0.001 & 0.000 \\
\hline 24-Methylene-cycloarthanol & $66.27 \pm 4.00$ & $82.28 \pm 4.11$ & $97.37 \pm 4.06$ & $101.33 \pm 6.40$ & 0.011 & 0.000 & 0.000 \\
\hline Cycloarthenol & $11.72 \pm 1.14$ & $13.02 \pm 1.33$ & $14.76 \pm 1.01$ & $17.10 \pm 1.25$ & 0.468 & 0.087 & 0.004 \\
\hline
\end{tabular}

Note: P2, "Montoro-Adamuz"; M1, "Los Pedroches"; M2, PDO "Baena"; M3, PDO "Priego de Córdoba"; ', mg/100g;

${ }^{b}$, mean \pm standard deviation; ${ }^{c}$, Test for independent samples by groups $(p)$ 


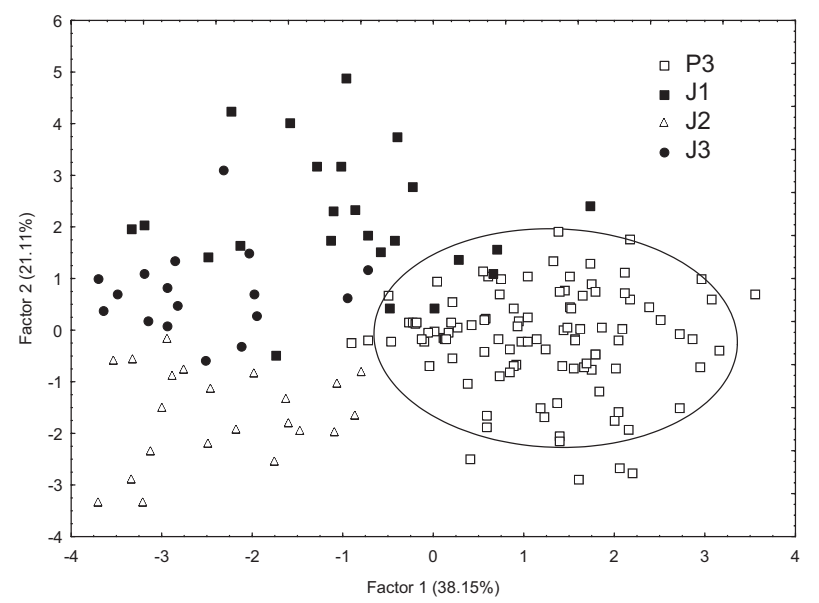

Figure 4.

Principal Component Analysis (PCA) of VOOs produced inside "Campiñas de Jaén" (P3), "Sierra Mágina" (J1), "Sierra del Segura" (J2) y "Sierra Sur" (J3).

correspond to the villages where the virgin olive oils of P2 are produced. Inside this ellipse there are also two samples of $\mathrm{M} 1$ that belong to VOOs produced in Pozoblanco (M1), $30 \mathrm{~km}$ away from Espiel, harvested in the two successive years. The rest of the samples of $\mathrm{M} 1$ are placed in the upper, right-hand side of the plot while the samples of VOOs produced in PDOs Baena (M2) and Priego de Córdoba (M3) are placed in the upper, left-hand side of the plot. No differences were observed among the samples for these PDOs.

\subsection{Studying a potential PDO surrounded by olive orchards with the same cultivars but different soils and climate}

The third PDO that was studied, Campiña de Jaén (P3), covered a large extension and is surrounded by counties that belong to registered PDOs. All these areas form the province of Jaen, where the main cultivar is Picual, accounts for $80 \%$ of the Spanish olive oil production. Other minor cultivars of the province are Arbequina, Manzanillo de Jaén and Royal. Among the surrounding areas, the PDO Sierra del Segura (J2) is characterized by a singular orography, with a high altitude $(900 \mathrm{~m})$ and a different soil. This fact explains that more compounds were selected by the procedure of Brown-Forsythe with a $\mathrm{p}<0.001$ to distinguish oils from this PDO and P3 (campesterol, $\beta$-sitosterol, copaene, 24-methylene-cycloarthanol, tridecene) (Table 5). Two compounds, copaene and phytol, were able to classify the samples from P3 and $\mathrm{J} 1, \mathrm{~J} 2$, J3 simultaneously due to a particularly low concentration in P3. Copaene is a monounsaturated sesquiterpene that is commonly identified in all varieties (Guinda et al., 1996). The selection of copaene as a traceability marker for geographical identification agrees with Zuninet et al. (2005), who used this compound together with other terpenoid hydrocarbons to distinguish Italian and non-Italian oils. Furthermore, this compound has been previously used in the geographical identification of oils by other authors in previous works (Aparicio et al., 1991a). Phytol, a diterpene alcohol, has also been selected as a variable in multivariate models to classify VOOs according to their geographical origin (Aparicio et al., 1991a; Alessandri et al., 1999). The selection of this compound, which is a radical of chlorophyll, is probably partially due to the correlation between phytol and the degree of ripeness of the olives (Aparicio et al., 1991b).

Despite the Brown-Forsythe test showing that some variables are able to distinguish the P3 samples from others, the multivariate procedure of PCA displays a separation of samples that is slightly worse than in the two previous cases. One of the reasons is the clear abundance of Picual cultivar with respect to the others. In addition, the

Table 5

Values (mean \pm standard deviation) of the chemical compounds characterizing VOOs produced in "Campiñas de Jaén" (P3) and its neighbouring orchards

\begin{tabular}{lrrrrrcc}
\hline Chemical Compound & \multicolumn{1}{c}{ P3 } & \multicolumn{1}{c}{ J1 } & \multicolumn{1}{c}{ J2 } & J3 & P3 vs.J1 $^{\mathbf{c}}$ & P3 vs.J2 $^{\mathbf{c}}$ & P3 vs.J3 $^{\mathbf{c}}$ \\
\hline Gramisterol & $0.71 \pm 0.02$ & $0.57 \pm 0.06$ & $0.63 \pm 0.04$ & $0.63 \pm 0.04$ & 0.005 & 0.077 & 0.154 \\
Stigmasterol & $1.23 \pm 0.04$ & $0.97 \pm 0.05$ & $1.04 \pm 0.07$ & $1.10 \pm 0.09$ & 0.002 & 0.031 & 0.212 \\
Campesterol & $4.84 \pm 0.05$ & $4.61 \pm 0.16$ & $4.10 \pm 0.10$ & $4.26 \pm 0.09$ & 0.091 & 0.000 & 0.000 \\
$\beta$-Sitosterol & $123.17 \pm 1.41$ & $119.99 \pm 3.31$ & $107.84 \pm 2.20$ & $112.35 \pm 2.45$ & 0.370 & 0.000 & 0.012 \\
$\alpha$-Copaene & $0.03 \pm 0.01$ & $0.04 \pm 0.00$ & $0.06 \pm 0.00$ & $0.04 \pm 0.01$ & 0.000 & 0.000 & 0.000 \\
24-Methylene-cycloarthanol & $78.05 \pm 2.16$ & $101.84 \pm 9.46$ & $85.81 \pm 4.29$ & $91.95 \pm 7.44$ & 0.000 & 0.159 & 0.044 \\
Phytol & $2.75 \pm 0.06$ & $3.18 \pm 0.19$ & $3.37 \pm 0.31$ & $3.45 \pm 0.33$ & 0.011 & 0.002 & 0.002 \\
Tricosane & $0.17 \pm 0.01$ & $0.26 \pm 0.07$ & $0.14 \pm 0.01$ & $0.13 \pm 0.01$ & 0.002 & 0.013 & 0.004 \\
Tridecene & $0.51 \pm 0.01$ & $0.41 \pm 0.03$ & $0.34 \pm 0.02$ & $0.34 \pm 0.04$ & 0.000 & 0.000 & 0.000 \\
Muurolene & $0.00 \pm 0.00$ & $0.01 \pm 0.00$ & $0.02 \pm 0.00$ & $0.01 \pm 0.00$ & 0.002 & 0.000 & 0.000 \\
\hline
\end{tabular}

Note: P3, "Campiña de Jaén"; J1, "Sierra de Mágina"; J2, "Sierra del Segura"; J3, "Sierra Sur"; ", mg/100g; ", mean \pm standard deviation;

', Test for independent samples by groups $(p)$ 
large extension of P3 ( 300.000 ha) makes it difficult to produce virgin olive oils that are singularity different from others because of a particular climate and/or soil. The PCA plot also points out the different composition of oils from J2 (Sierra del Segura), in the upper part of the plot, as mentioned above.

The study of these three cases shows that each PDO has a different degree of difficulty to be differentiated from the oils produced in the surrounding areas. The two first cases were relatively easy to classify although the result proves that it is difficult to establish discreet limits defining the PDO area, as some oils from the mills located near the border line were misclassified. At the same time, the third case involves a major challenge in the classification of samples due to the predominance of a single variety (Picual) and the large extension of land the covers the olive groves, which lacks of a distinct climate or soil in comparison with the other areas. The chemical compositions of major and minor compounds provides a support to certify the singularity of PDO oils versus others and this information may be used by both administration and PDO councils to supplement arguments approving or denying new PDOs. Once a PDO is registered, the chemical information can be also useful to detect falsifications and mislabelling.

\section{ACKNOWLEDGEMENTS}

This research has been partially funded by the Spanish Ministry of Science and Innovation (Ramón y Cajal Program and AGL2008-01411).

\section{REFERENCES}

Alessandri, S., Cimato, A., Modi, G., Crescenzi, A., Caselli, S., Tracchi, S. 1999. Multivariate models to classify Tuscan virgin olive oils by zone. Grasas Aceites 50, 369-378.

Alonso, M.V., Aparicio, R. 1993. Characterization of European virgin olive oils using fatty acids. Grasas Aceites 44, 18-24.

Ajana, H., El Antari, A., Hafidi, A. 1998. Fatty acids and sterols evolution during the ripening of olives from the Moroccan Picholine cultivar. Grasas Aceites 49, 405410.

Aparicio, R., Alonso, V. 1994.Characterization of virgin olive oils by SEXIA Expert System. Prog. Lipid Res.33, 29-38.

Aparicio, R., Alonso, V., Morales, M.T. 1994a. Detailed and exhaustive study of the authentication of European virgin olive oils by SEXIA expert system. Grasas Aceites 45, 241-252.

Aparicio, R., Ferreiro, L., Alonso, V. 1994b. Effect of climate on the chemical composition of virgin olive oil. Anal. Chim. Acta 292, 235-241.

Aparicio, R., Ferreiro, L., Leardi, R., Forina, M. 1991a. Building decision rules by chemometric analysis: application to olive oil. Chemom. Intell.Lab.Syst. 10, 349-358.
Aparicio, R., Ferreiro, L., Rodríguez, J.L. 1991b. Characterization of foods merging relational and linear decision rules. An application to virgin olive oil of Malaga. Grasas Aceites 42, 132-142.

Aparicio, R. 2000. Characterization: Mathematical procedures for chemicalanalysis, in Harwood, J.L., Aparicio, R. (Eds.) Handbook of Olive Oil: Analysis and Properties. Aspen Publishers, Gaithersburg MA. pp. 285-354.

Aparicio, R., Luna, G. 2002. Characterisation of monovarietalvirgin olive oils. Eur. J. Lipid Sci. Technol. 104, 614-627.

Rallo L, Barranco D, Caballero JM, Del Rio C, Martin A, Tous J, Trujillo I.2005. Variedades de olivo en España. Junta de Andalucía, MAPA, Ediciones Mundi-Prensa. Madrid.

Benveniste, P. 2002. The Arabidopsis Book. American Society of Plant Biologists. Rockville, MD. http://www. aspb.org/publications.

Calvente, J.J., Aparicio, R. 1995. A fuzzy filter for removing interferences among membership grade functions. An application to pre-treatment of data in olive oil authentication. Anal. Chim. Acta $\mathbf{3 1 2}$, 281-294.

Cosio, M.S., Ballabio, D., Benedetti, S., Gigliotti, C. 2006. Geographical origin and authentication of extra virgin olive oils by an electronic nose in combination with artificial neural networks. Anal. Chim. Acta 567, 202-210.

De Caraffa, V.B.,Gambotti, C., Giannettini, J., Maury, J., Berti, L., Gandemer, G.2008. Using lipid profiles and genotypes for the characterization of Corsican olive oils. Eur. J. Lipid Sci. Technol. 110, 40-47.

D’Imperio, M., Dugo, G., Alfa, M., Mannina, L., Segre, A.L. 2007. Statistical analysis on Sicilian olive oils. Food Chem. 102, 956-965.

EC 1991. Characteristics of olive oil and olive pomace oils and onthe relevant methods of analysis. Off. J. Eur. Commun., No248/1991

EC. 2006. Council Regulation on the protection of geographical indications and designations of origin for agricultural products and foodstuffs. Off. J. Eur. Commun., No 510/2006.

Ferreiro, L., Aparicio, R. 1992. Influence of the altitude of the orchards in the olive oil chemical composition. Grasas Aceites 43, 149-156.

Frega, N., Lercker, G. 1986. Compenti lipidici minori della drupa di olivo in diversi stadi di maturazione. Riv. Ital. Sost. Grasse 63, 393-398.

Frías, L., García-Ortiz, A., Hermoso, M., Jiménez, A., Llavero del Pozo, M.P., Morales, J., Ruano, T., Uceda, M. 1991. Analistas de Laboratorio de Almazaras. Informaciones Técnicas, 6/91. Junta de Andalucía, Sevilla, Spain.

García-González, D.L., Aparicio, R. 2010. Research in olive oil: Challenges for near future. J. Agric. Food Chem. 58, 12569-12577

García-González, D.L., Morales, M.T., Luna, G., Aparicio, R. 2009. Stepwise geographical traceability of virgin olive oils by chemical traits modeled on ANN. Eur. J. Lipid Sci. Technol. 111, 1003-1013.

Guinda, A., Lanzón, A., Albi, T. 1996. Differences in hydrocarbons of virgin olive oils obtained from several olive varieties. J. Agric. Food Chem. 44, 1723-1726.

Morales, M.T., Angerosa, F., Aparicio, R. 1999. Effect of the extraction conditions of virgin olive oil on the lipoxygenase cascade: Chemical and sensory implications. Grasas Aceites 50, 114-121. 
Ninni, V. 1999. A statistical approach to the biosynthetic route of fatty acids in olive oil: Cross-sectional and time series analyses. J. Sci. Food Agric. 79, 21132121.

Olejnik, S. F., Algina, J. 1987. Type I error rates and powerestimates of selected parametric and nonparametric tests of scale. J. Educ. Stat. 12, 4561.

Olivier, D., Artaud, J., Pinatel, C., Durbec, J.P., Guérère, M.2006. Differentiation of French virgin olive oil RDOs by sensory characteristics, fatty acid and triacylglycerol compositions and chemometrics. Food Chem. 97, 382-393.

Pafundo, S.; Agrimonti, C., Marmiroli, N. 2005. Traceability of plant contribution in olive oil by amplified fragment length polymorphisms. J. Agric. Food Chem. 53, 6995-7002.

Sakouhi, F., Absalon, C., Flamini, G., Cioni, P.L., Kallel, H., Boukhchina, S. 2010. Lipid components of olive oil from Tunisian Cv. Sayali: Characterization and authenticity. C. R. Biol. 333, 642-648.

Stiti, N., Triki, S., Hartmann, M.A. 2007.Formation of triterpenoids throughout Oleaeuropaea fruit ontogeny. Lipids 42, 55-67.

Zunin, P., Boggia, R., Salvadeo, P., Evangelisti, F. 2005. Geographical traceability of West Liguria extravirgin olive oils by the analysis of volatile terpenoid hydrocarbons. J. Chromatogr. A 1089, 243-249.

Recibido: $5 / 7 / 11$ Aceptado: $17 / 8 / 11$ 